\title{
Offshore Wind Energy Resource Assessment from Satellite Data Observations and WRF in Porto Santo Island
}

\author{
Fabiola S. Pereira ${ }^{1,2}$, Carlos S. Silva $a^{2,3}$ \\ ${ }^{1}$ AREAM - Regional Energy and Environmental Agency of Madeira Autonomous Region, Funchal, 9020-105, Portugal. \\ $5 \quad{ }^{2}$ MIT Portugal Program, Instituto Superior Técnico (IN+), Lisbon, 1049-001, Portugal. \\ ${ }^{3}$ Center for Innovation, Technology and Policy Research (IN+), Instituto Superior Técnico, Lisbon, 1049-001, Portugal. \\ Correspondence to: Fabiola S. Pereira (fabiola.pereira@tecnico.ulisboa.pt)
}

Abstract. The vast majority of isolated electricity production systems such as Islands depends on fossil fuels. Porto Santo Island, a Portuguese UNESCO Biosphere Reserve candidate from Madeira Archipelago situated in the Atlantic Ocean, aims to become a sustainable territory in order to reduce its carbon footprint.

A sustainable pathway goes through the integration of renewable energy in the electricity production system, in particular, the potential of offshore wind energy.

The scope of this work has three main purposes: 1) the offshore wind resource assessment in Porto Santo Island, 2) the determination of a zone of interest regarding the combination of different parameters such us the bathymetry, distance to the coastline and integrated in the national situation plan of maritime space 3) the estimation of the annual energy production from the best-fitted Weibull Distribution.

In the first place, a methodology for data analysis was defined processing netcdf data regarding a ten year wind hindcast from WRF (Weather Research and Forecasting) atmospheric model at $100 \mathrm{~m}$ above mean sea level from Ocean Observatory, annual and monthly mean offshore wind energy resource maps were created and a comparison with about 20 year times series of surface winds derived from remotely satellite scatterometer observations at different locations was made. Results show that the average annual mean wind speeds reach the range of 6,6-7,6 m/s in specific areas, situated in the northern part of Porto Santo Island with a Weibull distribution shape parameter $(\mathrm{k})$ of 2,4-2,9. Based on the results, the wind resource assessment, the estimation of the annual wind energy production and capacity factors were calculated from the best-fitted Weibull distribution for each of the geographical coordinates selected.

Comparisons with observational data show that WRF model is a proficient wind generating tool. The technical energy production potential and a priority zoning for offshore wind power development is performed using wind turbine generators of 3.3 MW-8.0 MW capacity, that could generate between 12 and $26 \mathrm{GWh}$ of energy per year, while avoiding $\mathrm{CO}_{2}$ emissions. The results show that an offshore wind farm plan is an eligible choice, with an average annual wind power density reaching about $300 \mathrm{~W} / \mathrm{m}^{2}$ at $100 \mathrm{~m}$ height in the north region.

Keywords: offshore wind energy, satellite observations, Porto Santo Island, Weibull distribution.

\section{Introduction}

The European Union has set ambitious targets for the development of renewable energy: $20 \%$ of final energy consumption from renewable sources by 2020. European countries are willing to deliver on their 2020 renewable energy targets and will prepare their 2030 National Energy and Climate Plans (NECP) outlining their renewables trajectories to 2030. Wind energy will play a key role over the period, allowing many European countries to continue decarbonizing their power systems in a cost-effective way and to continue the transformation of their energy systems. It is expected that offshore wind will make a great contribution to this objective with a capacity up to $40 \mathrm{GW}$ of offshore wind to be installed by 2020 in the European Union which may rise to $150 \mathrm{GW}$ in 2030 (EWEA, 2018). Offshore wind power is emerging as an interesting renewable energy source for power generation, with the potential to mitigate climate change, increase energy security and stimulate the global economy. The technologies that have incited the most progress are larger, more effective turbines and improved foundations. 
The evolutions pathway of the offshore wind technology goes from the increase of the wind turbine rotor diameter in the pursuit of economies of scale, a multiple rotor turbine design, vertical axis turbines, the increase in wind farm size from 79,6 MW in 2007 to 561 MW in 2018 and more in the next years. In addition, the utilization of drones and UAV's for maintenance, monitoring and inspection activities in order to increase safety because equipment installations are being held in deeper waters, increasing the distance from shore and entailing major engineering challenges (WWEA, 2010). On the other hand, this will reduce the cost per MW, improving yield and operations and maintenance (O\&M) efficiencies. Floating offshore wind technology are applied at water depths above $50 \mathrm{~m}$ (semi-submersible, tension leg, spar). Most of the wind farms in construction are using turbines above $6 \mathrm{MW}$ and some demonstration projects start with 2-5 MW (EWEA, 2018).

50 Early stage wind resource assessments using meteorological models concentrated on low resolution, country-wide maps. More recent work concentrates on high resolution wind modeling, covering smaller territories, both for the objective of developing mesoscale and microscale modeling, and to assess the wind resource for eventual wind power development. Once the wind resource is properly assessed for a site, several models of wind turbines, including of various nominal capacities, can be integrated in the study to identify the most promising turbine model to maximize the energy production on the site. In this regard, the annual energy production constitutes the basis of analysis for the viability of a wind power plant.

Regarding the specific characteristics and challenges of isolated electricity production systems, such us Islands, offshore wind energy could be an eligible choice in order to increase the penetration of renewables in the electricity production system (Carvalho MG et al, 2003).

While the energy supply of most islands depends mainly on expensive oil derivatives' importation, the others are linked by usually a weak electricity grid connection to the mainland. Due to high energy costs the islands are proving to be excellent test beds for the introduction of new technologies, and some islands are trying to become $100 \%$ renewable islands, to satisfy their energy demand mainly or entirely from indigenous and renewable sources, thus increasing the security of supply, and employment opportunities, without necessarily increasing the costs.

The outermost regions such us specific Islands and Archipelagos provide a European presence in strategic areas of the world and have exceptional characteristics that make them excellent laboratories for research and innovation in renewable energies. For this reason, the case study of an offshore wind farm in the coast of Porto Santo Island, that is part of Madeira Archipelago which is an outermost region, was selected, in order to reduce dependence of fossil fuel imports and increase the sustainable development in the Island.

\subsection{Objectives}

70 This paper aims to describe the determination of the offshore wind resource potential in Porto Santo Island, the definition of potential zones of interests and the estimation of the annual energy production (AEP) from different offshore wind turbine generators.

\section{Case study: Porto Santo Island}

75 Porto Santo is an island of the Madeira archipelago, in the North Atlantic Ocean, which is located about $500 \mathrm{~km}$ from the North African coast, in the northeast of the Madeira Island, see Figure 1. This island has a population of 5168 inhabitants, a total area of $43 \mathrm{~km}^{2}$ with 120 inhabitants $/ \mathrm{km}^{2}$.

The annual energy production in Porto Santo in 2017 was 33,2 GWh with an installed capacity of 20,7 MW (EEM, 2017) The energy demand increases substantially on July, August and September essentially due to tourist activity. The peak power was 7,69 MW in August. The contribution of the energy mix produced by primary energy source in 2018 represents $11,8 \%$ in $\mathrm{PV}$, wind onshore $3,9 \%$ while total fossil fuel in the electricity sector represents $84,8 \%$ of the energy mix. The Island is highly dependent on fossil fuel-based energy consumption with a total $\mathrm{CO}_{2}$ emission of $18,47 \mathrm{kton}$ corresponding to $555,5 \mathrm{~g} \mathrm{CO}_{2} / \mathrm{kWh}$ (EEM, 2017). In the context of climate change, renewable energy can play a significant role in reducing anthropogenic greenhouse gas emissions. Based on the experiences from around the world, five key factors can positively influence the 

and infrastructure, environmental and social responsibility and cost reductions. However, offshore wind resource assessment is the first, and necessary, key step in the development phase of offshore wind power plants.

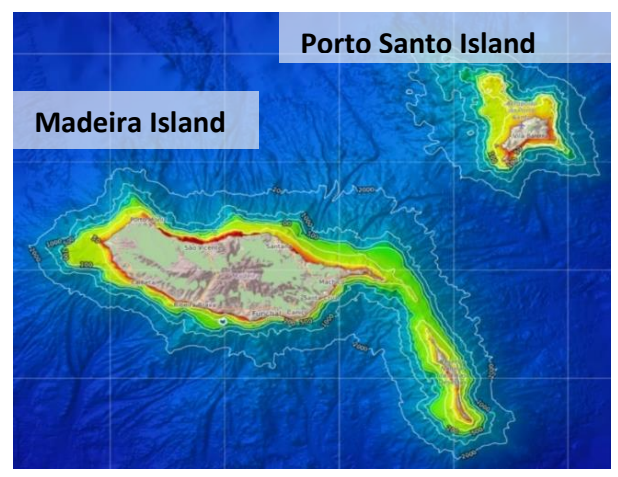

Figure 1 Geographical location and bathymetry of Madeira and Porto Santo Island.

\section{Methodology}

\subsection{Offshore wind resource assessment}

Offshore wind resource assessment is the first key step in order to identify and select a potential zone of interest by integrating specific wind profile, wind direction, variability regarding height and distance from shore with economic, social, political and environmental parameters for a multi criteria decision making solution.

In this study, offshore wind resource maps were created considering two data sources: 1) Weather Research and Forecasting (WRF) atmospheric model regarding 10-year historic data base for the Typical Meteorological year from 2007 until 2016 (80x50 km², distance of $10 \mathrm{~km}$, applied under nesting grids on three domains with resolutions of $9 \mathrm{~km}, 3 \mathrm{~km}$ and $1 \mathrm{~km}$, wind speed at $100 \mathrm{~m}$ height) source data from Ocean Observatory and 2) Time series of surface winds (10m height) from remotely scatterometer observations (L4) a 20-year historic data from 1994 until 2016, data source from IFREMER.

For this purpose, mean hourly wind speeds data were processed in netcdf format, monthly and annual resource maps were computed.

\subsection{Prandtl logarithmic law}

The Prandtl logarithmic law as described in eq.1 gives a good representation of the variation of the mean wind speed with height. Comparison between measurements and calculations of the log-law model showed that the model can describe the change of mean wind speed extrapolating for different heights all the data at a reference height $z_{R}$ and obtain with reasonable accuracy the mean wind speed turbine at the hub height $z$ which is $100 \mathrm{~m}$.

$$
u(z)_{u}=\left(z_{R}\right) \frac{\ln \left(\frac{z}{z_{0}}\right)}{\ln \left(\frac{z_{R}}{z_{0}}\right)},
$$

Where $u(z)$ is the mean wind speed at height $z, u\left(z_{R}\right)$ is the mean wind speed measured at the reference height $z_{R}$ and $z_{0}$ is the roughness length determined by the surface condition of the surface.

\subsection{Method of bins}

This method is characterized by the representation of the wind speed data in a histogram, obtained by splitting the range of data into equally sized bins, called classes. Each class is represented by the middle value of the bin. Therefore, each bin with $1 \mathrm{~m} / \mathrm{s}$ width has associated a relative frequency which is calculated by the Eq. (2). The frequency, i.e., the number of occurrences in each bin, is denoted $f_{i}\left(u_{i}\right)$ and the number of wind velocity readings equals:

$$
n=\sum_{i=1}^{N=25} f_{i}\left(u_{i}\right)=8760,
$$




\subsection{Weibull distribution functions}

The Weibull Distribution has been used to represent wind speed distributions for application in wind loads studies for a long time. The Weibull distribution function, which is a two-parameter function, in wind energy analysis it is used to represent the wind speed probability density function (pdf), expressed mathematically (Spera, 1995; Persaud et al., 1999) as:

$$
f(u)=\left(\frac{k}{c}\right)\left(\frac{u}{c}\right)^{k-1} \exp \left[-\left(\frac{u}{c}\right)^{k}\right],
$$

Where $f(u)$ is the probability of observing wind speed $u, k$ is the dimensionless Weibull shape parameter (or factor), and c the Weibull scale parameter. The $k$ values range from 1,5 to 3,0 for most wind conditions, depending on the variability the wind. Smaller $k$ values correspond to more variable (gusty) winds.

In this case study the parameters of the Weibull wind speed distribution for wind energy analysis were determined by the least squares method and graphic method. The application of each method is demonstrated using a mean hourly wind speed data set measured in a year.

\subsubsection{Analytical procedure - Least Squares Method}

140 It was assumed a dataset that constitute a pair $(x i, y i)=(x 1, y 1), \ldots,(x n, y n)$. The least squares principle minimizes the vertical distance between the data points and the straight line fitted to the data. Both parameters $\mathrm{k}$ and $\mathrm{c}$ were calculated in order to minimize the mean squared error (MSE) given in the following equation by changing both $k$ and $c$ to minimize quadratic error:

$$
M S E=\frac{1}{n} \sum_{i=1}^{n=25}\left[f\left(u_{i}\right) L S-f\left(u_{i}\right) \text { Experimental }\right]^{2},
$$

Where $f\left(u_{i}\right) L S$ is obtained by substituting the parameters $k$ and $c$ in Eq. (3) while $f\left(u_{i}\right)$ Experimental is the experimental probability density function values regarding wind speed histogram.

\subsubsection{Graphical procedure - Linear Regression}

The Weibull cumulative distribution function (cdf) was transformed to allow the computation of a linear regression in order to obtain the shape and scale parameter, mathematically the cdf equation it is given as:

$$
\begin{gathered}
f(u)=-\frac{d F(u)}{d u} . \\
\text { where } \ln [F(u)]=-\left(\frac{u}{c}\right)^{k}, \\
\text { and } \ln [-\ln [F(u)]]=k \ln (u)-k \ln (c),
\end{gathered}
$$

Applying a linear regression it is possible to obtain the correlation between these variables and obtain the linear Eq. (8): $Y=$ $A X+B$, where the shape parameter $k$ is the slope $(A)$ and from the interception in the $y$-axis we can calculate the scale parameter $c$ which is given by the mathematical Eq. (9): $c=\exp \left(-\frac{B}{A}\right)$.

\subsection{Power Curve - Sigmoid Approximation}

In this procedure was estimated the parameters $c 1$ and $c 2$ of the sigmoid function Eq. (11) in order to minimize the mean squared error by changing both $\mathrm{c} 1$ and $\mathrm{c} 2$ according to the following eq.

$$
M S E=\frac{1}{n} \sum_{i=1}^{n}\left[P_{e}(i) \text { Manufacturer }-P_{e}(i) \text { Sigmoid }\right]^{2},
$$

160 The results are presented as an analytical performance curve after the best fitting of the sigmoid function to the manufacturer power curve currently available that can be used in assessing the power output as subject to the given wind regime, thus providing a practical and straightforward tool for power potential assessment. The sigmoid function applied is the following:

$$
P_{e}=\left\{\begin{array}{cr}
P_{e} & u<u_{0} \\
\frac{P_{e}}{1+\exp \left(-\frac{u-c_{1}}{c_{2}}\right)} & u_{0} \leq u<u_{N} \\
P_{e}=P_{N} & u_{N} \leq u \leq u_{\max } \\
P_{e}=0 & u>u_{\max }
\end{array}\right\},
$$




\subsection{Estimation of annual energy production}

The assessment of estimated output energy is a key issue in the design and sizing of wind generation projects. Further, its accuracy and reliability can benefit from the use of actual power curve of the wind turbine generator that furnish the response of the generator to the wind regime under consideration further described in method 1 or by calculating according to method 2 the best sigmoid power curve approximation $P_{e}$. Furthermore, regarding the calculation of the cumulative distribution function, $\mathrm{F}(\mathrm{u})$ according to Eq. (6) it is estimated the annual energy produced by the wind turbine of the manufacturer.

\subsubsection{Method 1 - Direct Method}

The direct method combines the method of bins which divides the average hourly wind speed data set in classes (bins) with the wind turbine generator power curve in order calculate the annual energy produced.

$$
\begin{aligned}
& E_{a}=8760 \int_{u_{o}}^{u \max } f(\bar{u}) P_{e}(\bar{u}) d \bar{u}, \\
& \text { where } E_{a}=\sum_{u_{0}}^{u_{\max }} f_{r}(u) P_{e}(u),
\end{aligned}
$$

\section{$175 \quad$ 3.6.2 Method 2}

This method allows to estimate the annual energy produced through the analytical computation of the Weibull Distribution approximation for the wind speed and the sigmoid approximation for the wind turbine power curve.

$$
E_{a}=8760 \sum_{i=u_{1}}^{u_{\max }}\left[(F(i-1)-F(i)) \frac{P_{e}(i)+P_{e}(i-1)}{2}\right],
$$

The energy generated by the offshore wind farm is estimated by applying a generic power curve or by calculating the sigmoid approximation for four offshore class wind turbine generators (WTG) available on the market, i.e. 3.3MW, 5MW, 7MW and $8 \mathrm{MW}$. Wake effect plays an important role in reducing the energy production of a wind power plant. Along with the wind direction, this effect is directly related to the positions of each WTG with respect to the other WTGs, the dimensions of the WTGs, and the geophysical characteristics of the site.

\section{Results}

\subsection{Offshore wind resource assessment}

Results from the WRF atmospheric model along with satellite observations database were post-processed to generate monthly mean wind speeds at $100 \mathrm{~m}$ in Porto Santo. It is possible to conclude that predominant winds are from East to West in Porto Santo. During March, July and December mean wind speed can reach a peak of $9 \mathrm{~m} / \mathrm{s}$ across specific locations. During an annual base hourly mean wind speed profile across the area range from $5,6 \mathrm{~m} / \mathrm{s}$ to approximately $9 \mathrm{~m} / \mathrm{s}$.

Applying the Weibull distribution function across the study area from Eq. (3) it was possible to determine the shape $(k)$ and scale $(c)$ Weibull parameters in the typical meteorological year (TMY). Results showed that the scale parameter $(c)$ range from $7,5 \mathrm{~m} / \mathrm{s}$ to $8,3 \mathrm{~m} / \mathrm{s}$ which is the mean wind speed in the TMY. In addition, the shape parameter $(k)$ calculated across the study area is 2,4 to 2,8 indicating a constant variability which has a great potential. Figures 2 and 3 represent both parameters for Porto Santo Island.
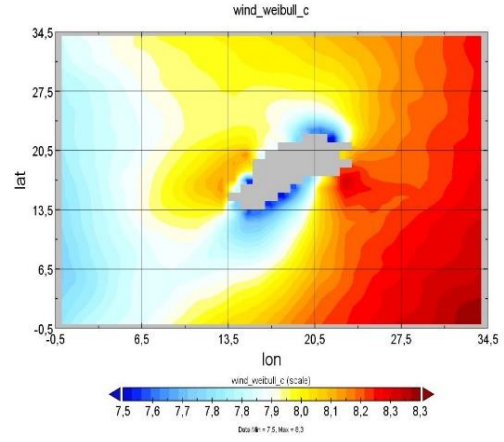

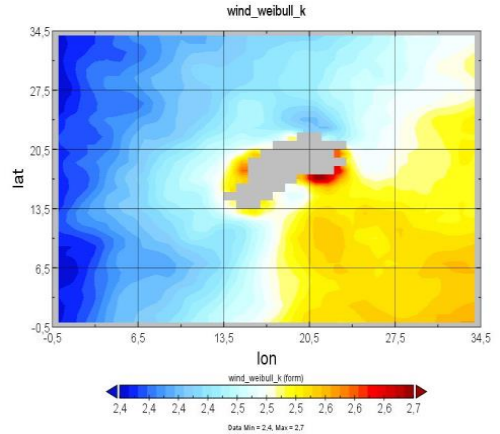

Figure 2 and 3: Annual map of the Weibull scale parameter (c) and shape parameter (k) in Porto Santo. 


\subsection{Potential zones of interest}

In order to carry out an assessment of potential sites for the integration of offshore renewable energies a multivariable analysis is necessary, regarding local bathymetry, distance to the coast, tourism, fishing areas, aquaculture areas, facilities and infrastructures for the production of energy from renewable sources, transport routes and flow of maritime traffic, military training areas, conservation of nature, species and protected areas, areas of extraction of raw materials, scientific research, route of submarine cables, pipelines and the underwater cultural heritage.

210 Due to the fact that the South part of the Island has greater constraints on maritime transport and tourism activities it was selected an area in the northern part of the island and integrated in the national situation plan of maritime space (PSOEM).

Furthermore, in order to the estimate the annual energy production 10 geographical coordinates were studied in order to compare results and profiles and two offshore wind sites were selected: EOPS1 and EOPS2, with a respectively distance of 7 $\mathrm{km}$ and $12 \mathrm{~km}$ from the shore in order to compare and analyze the most suitable zones. It was also defined, regarding interviews, the eligible criteria for potential areas of the offshore wind farm in order to complete the resource assessment analysis.

\subsection{Wind speed bins (classes)}

In order to proceed to the statistical analysis of the wind speed data from the WRF model data base, hourly average values were defined into 22 bins (classes) with $1 \mathrm{~m} / \mathrm{s}$ width of amplitude of classes. All the 8760 average wind speed values were classified in intervals starting in $0 \leq \mathrm{u}<1$ until $22 \leq \mathrm{u}<23$ until reached the 22 classes. The frequency of occurrence of the 8760 average wind speed sample was calculated according to Eq. (2) and represented in a histogram after computing the statistical analysis:

\begin{tabular}{|c|c|}
\hline \multicolumn{2}{|c|}{ Statistical Analysis } \\
\hline Mean & 7,13 \\
\hline Standard Error & 0,03 \\
\hline Median & 7,1 \\
\hline Mode & 6,8 \\
\hline Standard Deviation & 3,07 \\
\hline Sample Variance & 9,48 \\
\hline Minimum & 0,2 \\
\hline Maximum & 22 \\
\hline Sample $\mathrm{n}$ & 8760 \\
\hline
\end{tabular}

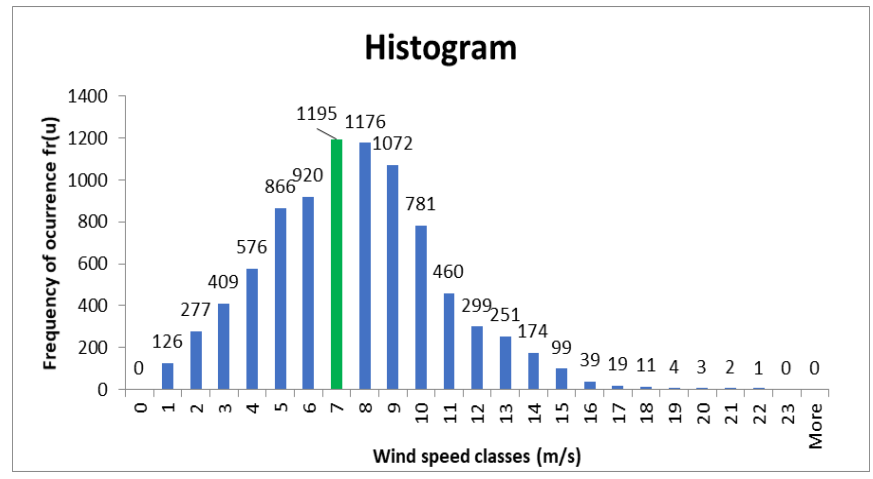

Table 1: Statistical Analysis of wind speed data.

Figure 4: Wind speed Histogram and statistical analysis.

Analyzing Figure 4 we can conclude that the mean speed class 7 has the highest occurrence during an annual base, indicating that in the site this is the most predominant wind speed.

\subsection{Weibull distribution at specific geographical coordinates}

Applying the methodology described in the previous section to both specific geographical coordinates selected (EOPS1, EOPS2) it was determined the wind profile and characteristics of these two offshore wind sites. In summary, Table 2 compares the results obtained regarding wind speed data from WRF model and satellite observations computing the Weibull from the maximum likelihood estimation method (MLE) and the least squares estimation method (LSE).

\begin{tabular}{|c|c|c|c|c|c|c|c|c|c|}
\hline Location & $\begin{array}{c}\text { Mean hourly } \\
\text { wind speed } \\
(\mathbf{m} / \mathbf{s})\end{array}$ & $\begin{array}{c}\mathbf{k} \\
\text { MLE }\end{array}$ & $\begin{array}{c}\mathbf{k} \\
\mathbf{L S E}\end{array}$ & $\begin{array}{c}\text { k } \\
\text { Sat. data }\end{array}$ & $\begin{array}{c}\text { c } \\
\text { MLE } \\
(\mathbf{m} / \mathbf{s})\end{array}$ & $\begin{array}{c}c \\
\text { LSE } \\
(\mathrm{m} / \mathrm{s})\end{array}$ & $\begin{array}{c}\text { c } \\
\text { Sat. data }\end{array}$ & Bathymetry (m) & $\begin{array}{c}\text { Distance } \\
\text { to shore } \\
(\mathbf{k m})\end{array}$ \\
\hline EOPS1 & 7,1 & 2,43 & 2,85 & 2,97 & 7,97 & 8,5 & 8,23 & 58,4 & 7 \\
\hline EOPS2 & 7 & 2,41 & 2,85 & 2,97 & 8 & 8,5 & 8,34 & 43,8 & 12 \\
\hline
\end{tabular}


Table 2: Comparative Analysis of Weibull parameters obtain from WRF model and satellite observation applying Least squares estimation method (LSE) and maximum likelihood estimation method (MLE).

The Weibull function provides a good fit representation of the wind speed data. The mean wind speed is $7,1 \mathrm{~m} / \mathrm{s}$ and deviations between $k$ LSE and $k$ Satellite was $4 \%$ and from $c$ LSE and $c$ Satellite data was 3\%. A more significant deviation was observed between parameters calculated applying MLE method. In addition, it was estimated the cumulative distribution function (CDF) by applying Eq. (5 to 7) in order to compute the annual energy produced.

\subsection{Annual energy production (AEP) and capacity factor (CP)}

Applying the mathematical Eq. (13 to 14) for an annual basis ( 8760 hours) the annual energy produced by each wind turbine generator is represented in the following figure:
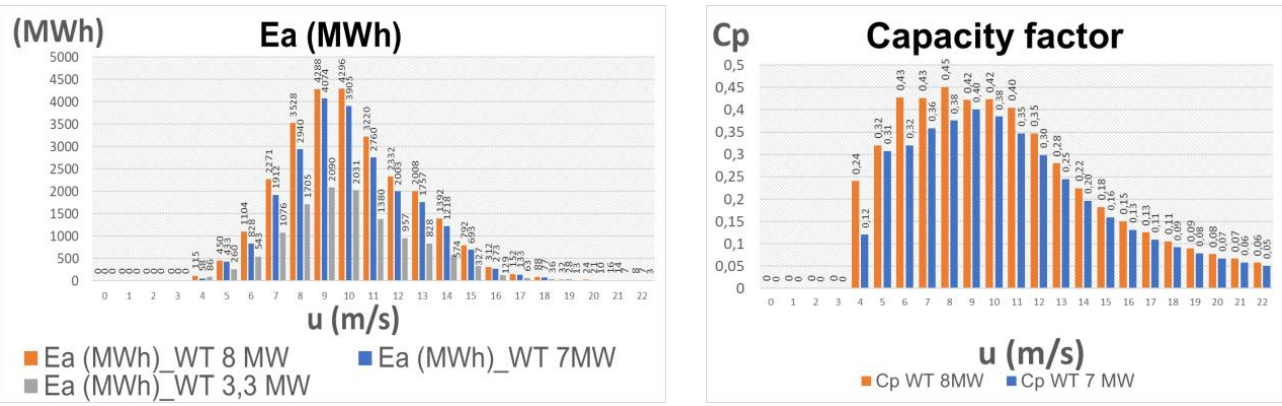

Figure 5 and 6: Comparative analysis of estimated annual energy production from different wind turbine generators for EOPS1 and Capacity factors of WTG 7MW and 8MW.

Analyzing results obtained from the three wind turbine generators (Figure 5) and in both location EOPS1 and EOPS2 (Table 2) it is possible to conclude that annual energy production depends on the wind turbine selected. In the case of 7 MW WTG, total annual energy production is $23,1 \mathrm{GWh}$ and if $8 \mathrm{MW}$ WTG is selected the annual energy production is $26,43 \mathrm{GWh}$. Total operating hours are approximately $3305 \mathrm{~h}$ and $3303 \mathrm{~h}$ respectively for each WTG.

Regarding the case study selected and both sites EOPS1, EOPS2 results showed that $7 \mathrm{~m} / \mathrm{s}$ is the mean hourly wind speed. Although WTG performance on these two sites are similar due to a short wind variability, by integrating a multivariable criteria approach EOPS1 could be more advantage than EOPS2.

EOPS1 has a lower distance to shore $(7 \mathrm{~km})$, it is more suitable to guarantee the access to the connecting point in the electricity grid and it could reduce costs regarding operation, maintenance of the offshore wind farm and submarine cables. In addition, the bathymetry selected was $58,5 \mathrm{~m}$ suitable for innovative floating wind offshore technologies.

\begin{tabular}{|c|c|c|c|c|c|c|c|c|}
\hline \multicolumn{4}{|c}{ Data Analysis } & \multicolumn{4}{c|}{ WT 7 MW } & \multicolumn{3}{c|}{ WT 8 MW } \\
\hline Bin Method & $\begin{array}{c}\mathrm{u} \\
\mathrm{m} / \mathrm{s}\end{array}$ & $\mathrm{fr}(\mathrm{u})$ & $\mathrm{u}(>\mathrm{Ea}) \mathrm{m} / \mathrm{s}$ & $\mathrm{h}$ & Ea anual (MWh) & $\mathrm{u}(>$ Ea) m/s & $\mathrm{h}$ & Ea anual $(\mathrm{MWh})$ \\
\hline EOPS1 & 7 & 1195 & 9 & 3305 & 23134 & 10 & 3303 & 26428 \\
\hline EOPS2 & 7 & 1169 & 10 & 3326 & 23285 & 10 & 3327 & 26618 \\
\hline
\end{tabular}

Table 3: Comparative analysis of results obtained in offshore wind sites EOPS1 and EOPS2.

The capacity factors were computed regarding previous estimations of energy production from wind turbines generator 3,3MW, $7 \mathrm{MW}$ and $8 \mathrm{MW}$. Analyzing Figure 6, it is possible to conclude that from the speed range $6 \mathrm{~m} / \mathrm{s} \leq \mathrm{u}<11 \mathrm{~m} / \mathrm{s}$ the capacity factor is approximately $40 \%$ considering the $8 \mathrm{MW}$ wind turbine. The $7 \mathrm{MW}$ wind turbine has a lower capacity factor in this wind speed ranges and from $5 \mathrm{~m} / \mathrm{s} \leq \mathrm{u}<8 \mathrm{~m} / \mathrm{s}$ the capacity factor is approximately $30 \%$ increasing for wind speeds of $9 \mathrm{~m} / \mathrm{s}$ to 10 $\mathrm{m} / \mathrm{s}$. For this reason, $8 \mathrm{MW}$ wind turbine could be more suitable. 


\section{Conclusions}

The study outlines a methodology for combining 20-year time series of surface winds derived from remotely scatterometer observations with results from 10-year wind hindcast from WRF model, in order to acquire and validate reconstructed offshore winds which can be used for offshore wind resource assessment, definition of the potential zones of interest and the estimation annual energy production in selected sites.

Winds were post-processed regarding the procedure as introduced in Section 3 by computing the division of mean hourly speed data in bins (wind classes) with a width of $1 \mathrm{~m} / \mathrm{s}$.

A comparison of Weibull parameters $(k, c)$ results from 10 year wind hindcast from WRF model and 20 year times series of surface winds derived from remotely satellite scatterometer observations was made in order to validate the overall wind resource potential in this territory.

The spatial distribution of the mean wind speeds shows that the northern part of the Porto Santo Island, is characterized by the most interesting wind resource for electricity generation.

Prior to investigating the energy-based feasibility of an offshore wind farm in Porto Santo Island, a zoning of offshore wind power development is recommended for medium to long-term planning. Building on a multi-criteria decision-making analysis for the site selection for offshore wind power plants, the load demand of electricity consumption is also considered as one of the major criteria for the siting of offshore wind power plants. In this approach, the energy generated by an offshore wind power plant is assumed to be transferred to the closest load in order to minimize losses. The criteria for the selection of the potential sites, along with their respective weight, consist of mean annual wind speed (50\%), water depth (15\%), distance from shore (15\%), and distance from load (20\%). For this reason, EOPS1 was considered more suitable than EOPS2.

Results show that the average annual mean wind speeds reach the range of $6,6-7,6 \mathrm{~m} / \mathrm{s}$ in specific areas, situated in the northern part of Porto Santo Island with a Weibull distribution shape parameter $(k)$ of 2,4-2,9. Depending on the wind turbine generator selected, these offshore wind sites could have an annual energy production in the order of 12,1 GWh (3,3 MW WTG) and 26,4 GWh (8 MW WTG) in the long term. With growing concerns about climate change, electricity generation facilities are increasingly assessed in regard to $\mathrm{CO}_{2 \mathrm{eq}}$ emissions, or their avoidances. By developing offshore wind power plants, the island could avoid 6,79 ktons (3,3MW WTG) to 14,8 ktons (8MW WTG) in the long term and injected to the grid depending on the electricity production system and intermittency.

Depending on the future $\mathrm{CO}_{2 \mathrm{eq}}$ emissions tariffs, these avoidances could have an interesting economic value, increasing the feasibility of offshore wind farms.

310 The results show that an offshore wind farm plan is an eligible choice, with an average annual wind power density reaching about $300 \mathrm{~W} / \mathrm{m}^{2}$ at $100 \mathrm{~m}$ height, in the north region, in Porto Santo Island. At the given offshore wind site, EOPS1, the equivalent hours of production at the wind turbine generator rated power is 3303 hours.

\section{Data availability}

Data source from WRF model were provided by the Ocean Observatory of Madeira. Satellite data observations were provided from the IFREMER.

\section{Author Contribution}

FSP computed netcdf data analysis, designed the methodology, computed calculations, figures and writing. CSS contributed in the research preparation and energy planning.

\section{Competing Interests}

The authors declare that they have no conflict of interest.

\section{Acknowledgements}

This work was financially supported by AREAM through the ARCWIND project (EAPA_344/2016), co-financed by the European Regional Development Fund through the Interreg Atlantic Area Programme. 


\section{References}

EWEA - The European Wind Energy Association, Wind energy scenarios for 2030 Wind energy scenarios for 2030, 2015.

EWEA - The European Wind Energy Association, Wind energy in Europe in 2018, 2018.

EEM - Madeira Electricity Company, Annual Report, 2017.

Junginger, A. Faaij, and W. C. Turkenburg, Cost Reduction Prospects for Offshore Wind Farms, Wind Eng., vol. 28, no. 1, pp. 97-118, Jan. 2004.

Snyder and Kaiser M. J., Ecological and economic cost-benefit analysis of offshore wind energy, Renew. Energy, vol. 34, no. 6, pp. 1567-1578, Jun. 2009.

Fingersh, M. Hand, and A. Laxson, Wind Turbine Design Cost and Scaling Model, 2006., NREL.

Spera, D. A. Wind Turbine Technology. Fundamental Concepts of Wind Turbine Engineering, New York: The American Society of Mechanical Engineers, 638 pp, 1995

Tester J., Drake E., Driscoll M., Golay M., Peters W.; Sustainable Energy: Choosing among options; Massachusetts Institute of Technology; 2012.

Burton T., Sharpe D., Jenkins N., Bossanyi E.; Wind Energy Handbook; John Wiley \& Sons, 1td; 2001.

Akins R.; Performance Evaluation of Wind Energy Conversion System Using the Method of Bins. Sand77-1375; 1978.

Cheng, S. K. and Chen, C. H., Estimation of the Weibull parameters with grouped data. Communications in Statistics: Simulation and Computation, 11, 197-216,1998

World Wind Energy Association WWEA(2010), World wind energy report.

Vestas wind system A/S. Offshore V164-8.0 MW V112-3.3 MW. 2013. Retrieved 20 November 2018.

Jonkman J, Butterfield S, Musial W, Scott G. Definition of a 5-MW reference wind turbine for offshore system development, 2009.

Cavalho D, Rocha A, Gesteira MG, Santos CS. Sensitivity of the WRF model wind simulation and wind energy production estimates to planetary boundary layer parameterizations for onshore and offshore area in the Iberian Peninsula. Appl Energy;135:234e46, 2014.

Mattar C, Borvarian D. Offshore wind powers simulation by using WRF in the central coast of Chile. Renew Energy;94:22e31, 2016.

Fitch AC, Olson JB, Lundquist JK, Dudhia J, Gupta AK, Michalakes J, et al. Local and mesoscale impact of wind farm as parameterized in a mesoscale NWP model. Mon Weather Rev;140:3017e38, 2012.

Laprise R. The Euler Equations of motion with hydrostatic pressure as as independent variable. Mon Weather Rev;120:197e207, 1982.

Carvalho MG et al, Increasing the supply of renewable energy sources in island energy systems. Int J Sustain Energy;23(4):177e86, 2003.

Shu ZR, Li QS, He YC, Chan PW. Observations of offshore wind characteristics by Doppler-LiDAR for wind energy applications. Appl Energy;169:150e63. 2016.

360 US Department of Energy, Energy Efficiency \& Renewable Energy. 80-meter wind maps and wind resource potential. 2010.

Natural Resources Canada. Canadian wind energy atlas. 2004. http://www. windatlas.ca.

Coppin PA, Ayotte KA, Steggel N. Wind resource assessment in Australia: a planner's guide. Canberra, Australia: Wind Energy Research Unit, CSIRO Land and Water; 2003.

Sahin B, Bilgili M. Wind characteristics and energy potential in Belen-Hatay. Turk Int J Green Energy;6:157e72, 2009.

Troen I, Petersen EL. European wind atlas. Riso National Laboratory, p. 656, 1989.

Rehman S, Aftab A, Al-Hadhrami LM. Development and economic assessment of a grid connected 20 MW installed capacity wind farm. Renew Sustain Energy Rev;15(1):833e8. 2011.

Himri Y, Rehman S, Setiawan AA, Himri S. Wind energy for rural areas of Algeria. Renew Sustain Energy Rev;16(5):2381e5,2012. 